\title{
In Vitro Evaluation of a Stable Monomeric Gold(II) Complex with Hematoporphyrin IX: Cytotoxicity against Tumor and Kidney Cells, Cellular Accumulation, and Induction of Apoptosis
}

\author{
Georgi Momekov, ${ }^{1}$ Dilyan Ferdinandov, ${ }^{1,2}$ Spiro Konstantinov, ${ }^{1}$ Sonja Arpadjan, ${ }^{3}$ Daniela Tsekova, ${ }^{3}$ \\ Galina Gencheva, ${ }^{3}$ Panayot R. Bontchev, ${ }^{3}$ and Margarita Karaivanova ${ }^{1}$ \\ ${ }^{1}$ Laboratory of Molecular Pharmacology and Experimental Chemotherapy, Department of Pharmacology, \\ Pharmacotherapy, and Toxicology, Faculty of Pharmacy, Medical University of Sofia, 2 Dunav Street, 1000 Sofia, Bulgaria \\ ${ }^{2}$ Department of Neurosurgery, "St. Ivan Rilski" University Hospital, Medical University of Sofia, 15 I.E. Geshov Street, \\ 1431 Sofia, Bulgaria \\ ${ }^{3}$ Department of Analytical Chemistry, Faculty of Chemistry, "St. Kliment Ohridsky" University of Sofia, \\ 1 J. Bourchier Boulevard, 1164 Sofia, Bulgaria
}

Correspondence should be addressed to Galina Gencheva, ggencheva@chem.uni-sofia.bg

Received 22 November 2007; Accepted 11 March 2008

Recommended by Lundmila Krylova

The antineoplastic potential of a stable monomeric $\mathrm{Au}(\mathrm{II})$ complex with hematoporphyrin IX (Hp), namely [Au(II)Hp ${ }_{-2 \mathrm{H}}$. $\left(\mathrm{H}_{2} \mathrm{O}\right)_{2}$ ], was investigated in a panel of tumor cell lines. The complex exhibits strong cytotoxicity, whereby the leukaemia- and lymphoma-derived cell lines are more sensitive, with $\mathrm{IC}_{50}$ values comparable to those of the reference anticancer drug cisplatin. In contrast, the solid tumor models are more sensitive to the platinum drug. A comparative assessment of both agents against the human kidney cell line $293 \mathrm{~T}$ has shown that $\left[\mathrm{Au}(\mathrm{II}) \mathrm{Hp}_{-2 \mathrm{H}} \cdot\left(\mathrm{H}_{2} \mathrm{O}\right)_{2}\right]$ is less cytotoxic. The gold complex induces oligonucleosomal DNA fragmentation in tumour cells following 24-hour treatment and hence its cytotoxic effect is at least partly mediated by induction of apoptotic cell death. A prominent intracellular gold accumulation was detected after treating tumor cells with $\left[\mathrm{Au}(\mathrm{II}) \mathrm{Hp}_{-2 \mathrm{H}} \cdot\left(\mathrm{H}_{2} \mathrm{O}\right)_{2}\right]$ which shows that its putative pharmacological targets are readily accessible after a short incubation period.

Copyright (C) 2008 Georgi Momekov et al. This is an open access article distributed under the Creative Commons Attribution License, which permits unrestricted use, distribution, and reproduction in any medium, provided the original work is properly cited.

\section{INTRODUCTION}

Cisplatin and the structurally related platinum-based drugs represent one of the most important classes of antineoplastic agents, being especially valuable for the treatment of germ cell cancer and a variety of other solid malignancies [1-3]. Despite their important clinical role, however, the platinumbased chemotherapeutics possess relatively low selectivity to malignant cells and hence their application is associated with significant dose-limiting organ toxicities [1]. Beside their unfavorable safety profile, the major limitation in the clinical application of the currently marketed platinum agents is the development of acquired resistance by the tumor cells [2]. Consequently, a significant interest is manifested towards the design and synthesis of cisplatin-dissimilar analogues with modified pharmacological properties capable of bypassing the cellular resistance mechanisms [4-6].

Considering the fact that the thermodynamic stability and kinetic behavior of the metal complexes in biological milieu and hence their biochemical and pharmacological properties depend greatly on the nature of the adductforming metal centers, it is well appreciated that a change of the metal ion could alter the antineoplastic activity [6]. Among the nonplatinum metal-based chemotherapeutics much attention has been paid to gold complexes [7]. Well known for their clinical antiarthritic application [8], the gold-based drugs have also attracted interest as potential antineoplastic agents with gold(I)-phosphine derivatives 


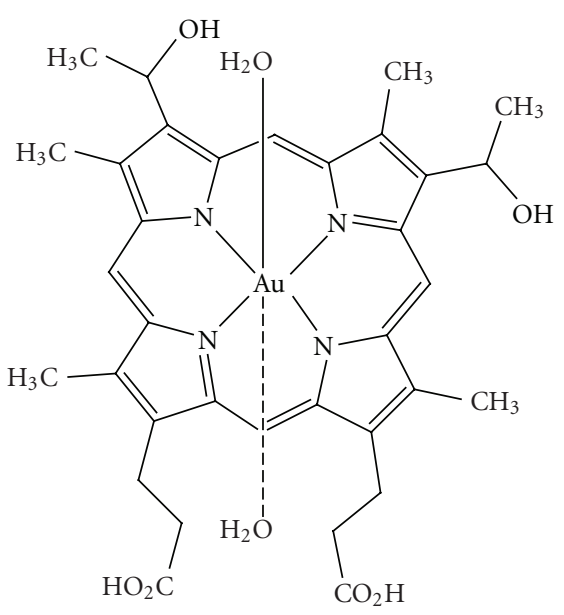

FIgURE 1: Chemical structure of the tested gold complex [Au(II) $\left.\mathrm{Hp}_{-2 \mathrm{H}} \cdot\left(\mathrm{H}_{2} \mathrm{O}\right)_{2}\right]$.

being among the most active in vivo against murine tumor models [9]. Currently, the greatest interest towards development of gold-based chemotherapeutics is focused on the $\mathrm{Au}$ (III) compounds which being isoelectronic with platinum(II) share the propensity of forming square planar complexes, analogous to cisplatin $[7,10]$. It could be anticipated that similar to $\mathrm{Pt}(\mathrm{II})$ compounds, the gold(III) species are capable of binding on DNA and this is the reason for their cytotoxicity. Unlike platinum(II), however, the gold(III) complexes are extremely unstable under physiological conditions which practically preclude the interest towards this class of metal-based drugs. In addition, the gold(III) complexes are highly reactive and are able to oxidize a series of biomolecules such as methionine, glycine, and albumin leading to a quick reduction to gold(I) or even to elemental gold [10-12]. It has been proven that the stability of $\mathrm{Au}(\mathrm{III})$ compounds can be augmented by bonding with nitrogen donor-containing bi- and multidentate chelating ligands such as ethylendiamine, cyclam, bipyridine, and so forth, that lower the redox potential of the metal center $[10,13,14]$. Recently, a large number of reports on the preparation, structural characterization, and cytotoxic studies of stable gold(III) complexes and organometallic compounds appeared in the scientific literature [10].

With regard to redox stability and kinetic behavior, the search for proper cytotoxic gold(II) complexes is an intriguing and previously unexplored area of anticancer drug design. Nowadays, the $\mathrm{Au}(\mathrm{II})$ oxidation state can be considered as a common state in gold chemistry. Despite the large number of stable diamagnetic dinuclear and polynuclear gold(II) complexes, the examples of mononuclear ones are scarce and most of them are with S-containing ligands [1517]. Recently, the synthesis and structural characterization of a stable monomeric hematoporphyrin $\mathrm{Au}(\mathrm{II})$ complex with general formula $\left[\mathrm{Au}(\mathrm{II}) \mathrm{Hp}_{-2 \mathrm{H}} \cdot\left(\mathrm{H}_{2} \mathrm{O}\right)_{2}\right]$ (Figure 1) and distorted octahedral structure has been reported [18]. Au(II) species are stabilized in the complex through coordination via the four nitrogen atoms of the porphyrin macrocycle and the two water molecules are in axial position.
The rationale design for synthesizing porphyrin-based metal complexes as anticancer drugs is based on their selective accumulation within malignant tissue together with participation in augmentation of the cytotoxicity upon light irradiation. Hence, such complexes are expected to behave like hybrid drugs with combined cytotoxic/phototoxic properties [4]. Brunner and coworkers have described large series of planar platinum(II)-porphyrin conjugates whereby the metal centers are coordinated with the porphyrin residues via the pendant functionalities [19-21]. Recently, we have synthesized and characterized three stable octahedral platinum hematoporphyrin complexes in the unusual oxidation state of platinum $3+$. In these complexes the hematoporphyrin ligand is coordinated as follows: via four pyrrole $\mathrm{N}$-atoms forming metalloporphyrin type complex; or by asymmetric coordination through two $\mathrm{N}$-atoms from adjacent pyrrole rings forming SAT-type complex; or by the side chains propionic $\mathrm{COO}^{-}$groups outside the porphyrin macrocycle. The complexes displayed significant cytotoxic and proapoptotic activities against human tumor cell lines [22].

This study deals with the cytotoxic activity of the newly synthesized stable gold(II) complex $\mathrm{Au}(\mathrm{II}) \mathrm{Hp}_{-2 \mathrm{H}} \cdot\left(\mathrm{H}_{2} \mathrm{O}\right)_{2}$ against a spectrum of tumor cell lines. Its effect on the human epidermal kidney cell line 293T has been studied as well in order to estimate the selectivity of cytotoxicity.

\section{MATERIALS AND METHODS}

\subsection{Chemicals and reagents}

RPMI-1640 and DMEM growth media, fetal calf serum, and L-glutamine were purchased from 3. Sigma-Aldrich Co, "St. Louis", Missouri, USA. (3-(4,5-dimethylthiazol-2yl)-2,5-diphenyltetrazolium bromide (MTT)- Triton X-100, gold standard, Tris $\mathrm{HCl}, \mathrm{DMSO}$, and EDTA were supplied from Merck Co.

The gold(II) complex with hematoporphyrin-[Au(II)$\mathrm{Hp}_{-2 \mathrm{H}} \cdot\left(\mathrm{H}_{2} \mathrm{O}\right)_{2}$ ] was synthesized as previously described [18]. The reference anticancer drug cisplatin was purchased from Sigma. Stock solutions of both agents were freshly prepared in DMSO and promptly diluted serially with RPMI-1640 medium to the desired extent. The DMSO concentration never exceeded $1 \%$ in the final dilutions obtained.

\subsection{Cell lines and culture conditions}

The T-cell leukaemia SKW-3 (a KE-37 derivative) (DSMZ No.: ACC 53); the nonHodgkin lymphoma DOHH-2 (DSMZ No.: ACC 47); the chronic myeloid leukaemias K562 (DSMZ No. ACC 10), and LAMA-84 (DSMZ No. ACC 168) as well as the urinary bladder carcinoma-derived 5637 (DSMZ No.: ACC 35) were obtained from DSMZ GmbH (Braunschweig , Germany). The human urinary bladder carcinoma cell line MGH-U1 was supplied by American Type Cell Culture (Rockville, MD, USA). The cells were maintained as suspension type cultures (leukaemias) or as adherent cultures (5637 and MGH-U1) in controlled environment: RPMI-1640 medium, supplemented by $10 \%$ heat-inactivated fetal calf serum and $2 \mathrm{mM}$ L-glutamine, at 
$37^{\circ} \mathrm{C}$ in a "Heraeus" incubator with $5 \% \mathrm{CO}_{2}$ humidified atmosphere. In order to keep cells in log phase, the cultures were refed with fresh RPMI-1640 medium two or three times/week.

\subsection{Cytotoxicity assay}

Cell viability was assessed using the standard MTT-dye reduction assay as previously described [23] with minor modifications [24]. Exponentially growing cells were seeded in 96-well flat-bottomed microplates $(100 \mu \mathrm{L} /$ well $)$ at a density of $1 \times 10^{5}$ cells per $\mathrm{mL}$ and after 24 -hour incubation at $37^{\circ} \mathrm{C}$; they were exposed to various concentrations of the tested complexes for 72 hours. For each concentration at least 8 wells were used. After the incubation with the test compounds MTT (3-(4,5-dimethylthiazol-2-yl)-2,5diphenyltetrazolium bromide (Sigma) solution $(10 \mathrm{mg} / \mathrm{mL}$ in PBS) was added $(10 \mu \mathrm{L} /$ well $)$. Microplates were further incubated for 4 hours at $37^{\circ} \mathrm{C}$ and the quantity of formazan product obtained was determined spectrophotometrically using a microprocessor-controlled multiplate reader (Labexim LMR-1) at $580 \mathrm{~nm}$. The cell survival fractions were calculated as percentage of the untreated control (untreated control $=100 \%$ ). The experimental data were transformed to sigmoidal dose-response curves using nonlinear regression analysis (GraphPad Prizm), which enabled the calculation of the corresponding $\mathrm{IC}_{50}$ values.

\subsection{DNA fragmentation analysis}

The characteristic for apoptosis mono- and oligonucleosomal fragmentation of genomic DNA was detected using "Cell Death Detection" ELISA kit (Roche Diagnostics, Germany). The exponentially growing MGH-U1, K-562, HDMY-Z, and SKW-3 cells were plated in sterile petry dishes and exposed to equipotent concentrations for 24 hours. Cytosolic fractions of $1 \times 10^{4}$ cells per group (treated or untreated) served as antigen source in a sandwich ELISA utilizing primary antihistone antibody-coated microplate and a secondary peroxidase-conjugated anti-DNA antibody. The photometric immunoassay for histone-associated DNA fragments was executed in accordance with the manufacturer's instructions at $405 \mathrm{~nm}$ using ELISA reader (Labexim LMR-1). The results were expressed as the oligonucleosome enrichment factor representing the ratio between the absorption in the treated versus the untreated control samples.

\subsection{Cellular accumulation kinetics}

Aliquots of $2 \times 10^{7}$ K-562 cells and HD-MY-Z cells (in $2 \mathrm{~mL}$ RPMI 1640) were placed in sterile petry dishes and exposed to different concentrations of the gold complex: $(12.5,25,50$, and $100 \mu \mathrm{M})$ for 30 or 60 minutes. After the exposure period, the cells were spun at $2000 \mathrm{rpm}$ for 5 minutes and the drug-containing medium was discarded. The cells were then washed thrice with phosphate buffered saline and aliquots were taken for counting and cell viability determination (trypan blue dye exclusion assay). Thereafter, the cells were digested in $50 \mu \mathrm{L} \mathrm{10 \%} \mathrm{Triton} \mathrm{X100} \mathrm{(EDTA)} \mathrm{for}$ 5 minutes, and $950 \mu \mathrm{L}$ mixture of concentrated hydrochloric acid and concentrated nitric acid (3:1) was added in order to allow complete decomposition of the cells, and dissolution of the accumulated gold complex for 1 hour. Following the complete decomposition of the cells, the volume of the samples was adjusted to $1 \mathrm{~mL}$ and the gold concentration was determined. The gold concentrations in the sample solutions higher than $0.5 \mu \mathrm{g} / \mathrm{mL}$ were determined using flame atomic absorption spectrometry (FAAS) with an air-acetylene flame (PYE UNICAM SP 1950). Lower gold concentrations were determined by electrothermal AAS using a Perkin-Elmer Zeeman 3030 spectrometer with an HGA-600 graphite furnace. The light source was a hollow cathode lamp for Au. The spectral bandpass was $0.7 \mathrm{~nm}$. Standard uncoated graphite tubes were used as atomizer. Only peak areas were used for quantification. The results were expressed as nmol gold $/ 10^{6}$ cells.

\subsection{Data processing and statistics}

The cytotoxicity assays were carried out in eight separate experiments, whereas the apoptosis induction evaluation was conducted in quadruplicate. The data processing exploited MS Excel and GraphPad Prizm software for PC. Student's $t$ test was performed with $P \leq .05$ taken as significance level.

\section{RESULTS}

\subsection{Cytotoxicity against tumor cell lines}

The cytotoxic potential of the novel Au(II) complex was studied in a panel of malignant cell lines, originating from leukaemias, lymphomas, and solid tumors. The results of the chemosensitivity screening program, following 72hour treatment, are summarized in Table 1. Throughout the screening investigation cisplatin was used as a positive control.

The cytotoxic effects of the $\mathrm{Au}(\mathrm{II})$ complex were evaluated using the concentration-response curves presented in Figure 2. The cellular viability was reduced significantly causing 50\% inhibition at micromolar concentrations in the majority of the cell lines tested.

Generally, the leukaemia and lymphoma-derived cell lines were more sensitive to the $\mathrm{Au}(\mathrm{II})$ complex and the $\mathrm{IC}_{50}$ values obtained were comparable to those of the referent anticancer drug cisplatin. Among them the most responsive tumor model was the T-cell leukaemia SKW3 (KE-37 derivative) (Table 1, Figure 2). Against this cell line the relative potency of $\left[\mathrm{Au}(\mathrm{II}) \mathrm{Hp}_{-2 \mathrm{H}} \cdot\left(\mathrm{H}_{2} \mathrm{O}\right)_{2}\right]$ even surpassed that of cisplatin. In contrast, the solid-tumorderived cell lines showed far more pronounced sensitivity to cisplatin as compared to the novel gold(II) complex. The murine neuroblastoma Neuro2A was resistant to both metal complexes. 
TABLE 1: $\mathrm{IC}_{50}$ values of $\mathrm{Au}(\mathrm{II}) \mathrm{Hp}_{-2 \mathrm{H}} \cdot\left(\mathrm{H}_{2} \mathrm{O}\right)_{2}$ and cisplatin against a panel of tumor cell lines assessed after 72-hour exposure (MTT-dye reduction assay).

\begin{tabular}{lccc}
\hline Cell line & Origin/Cell type & $\mathrm{IC}_{50}(\mu \mathrm{M})$ & cisplatin \\
\hline LAMA-84 & chronic myeloid leukaemia & $\mathrm{AI}) \mathrm{Hp}_{-2 \mathrm{H}} \cdot\left(\mathrm{H}_{2} \mathrm{O}\right)_{2}$ & 20.3 \\
K-562 & chronic myeloid leukaemia & 65.1 & 32.0 \\
SKW-3 & Ta) & 161.2 & 11.7 \\
DOHH-2 & nonHodl leukaemia & 7.6 & 35.0 \\
HD-MY-Z & Hodgkin's lymphoma & 50.1 & 12.2 \\
MGH-U1 & urinary bladder cancer & 43.1 & 5.9 \\
MCF-7 & breast cancer & 56.4 & 33.4 \\
SAOS-2 & osteogenic sarcoma & 166.8 & 15.2 \\
Neuro-2a & murine neuroblastoma & $>200$ & $>200$ \\
\hline
\end{tabular}

${ }^{(a)}$ KE-37 derivative;

(b) Formerly designated as EJ.

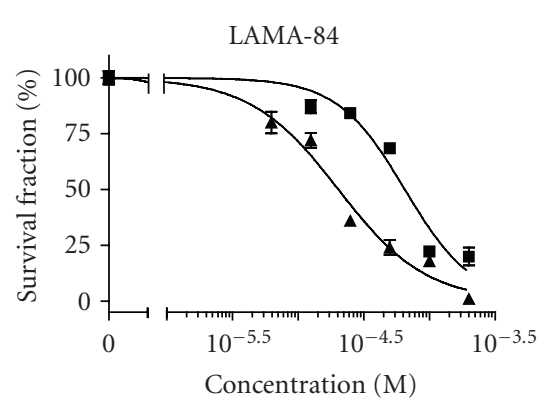

(a)

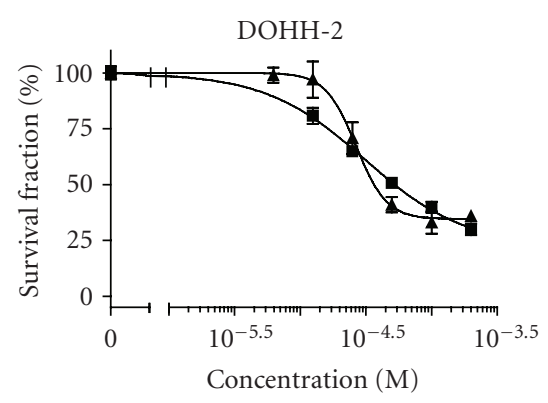

(d)

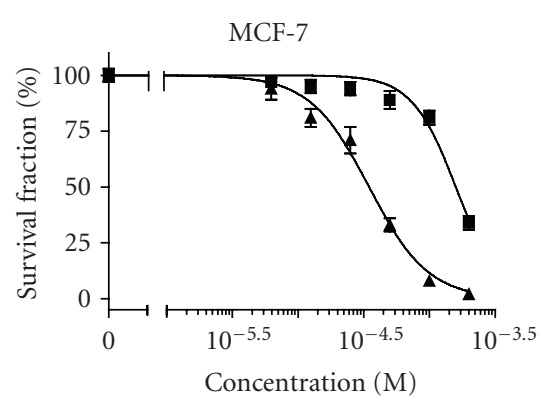

(g)

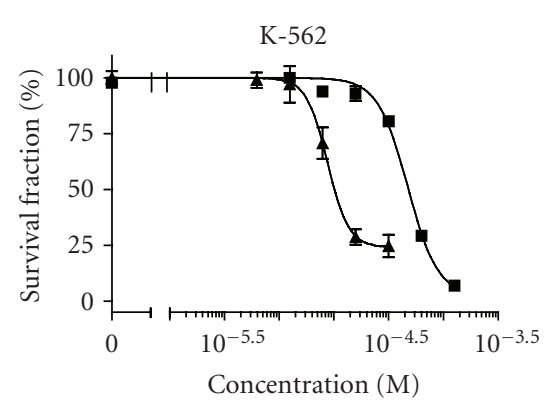

(b)

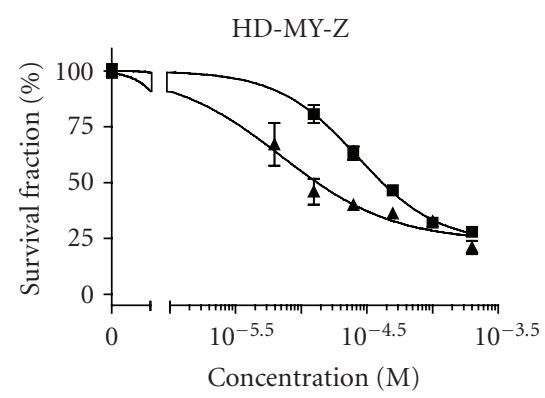

(e)

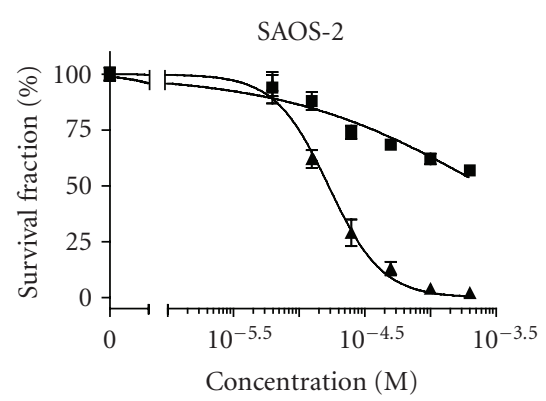

(h)

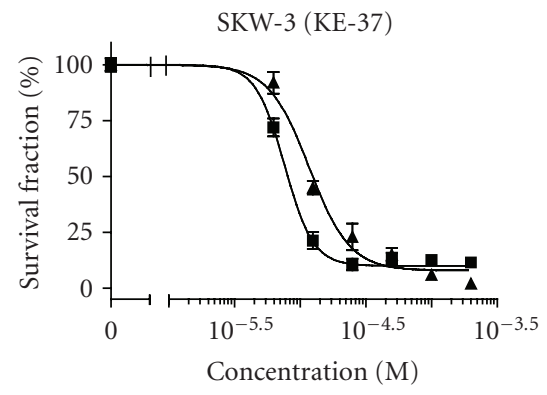

(c)

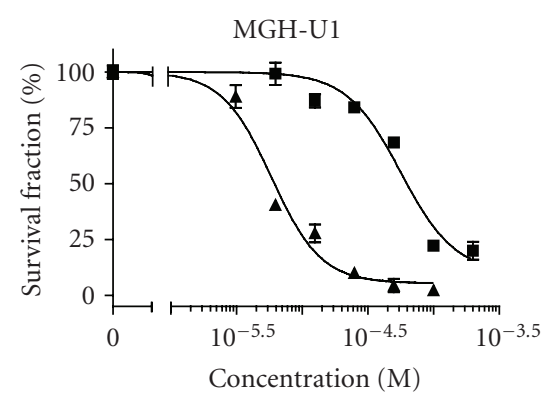

(f)

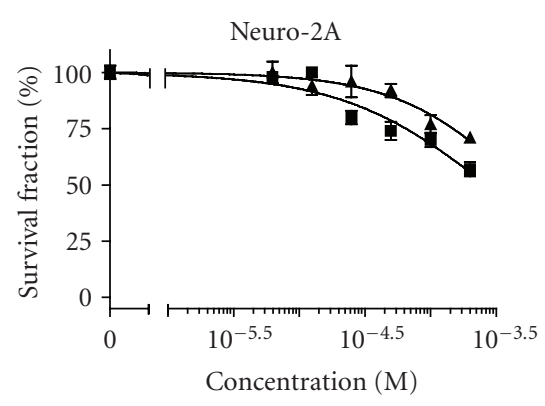

(i)

FIGURE 2: Concentration-response curves of $\left[\mathrm{Au}(\mathrm{II}) \mathrm{Hp}_{-2 \mathrm{H}} \cdot\left(\mathrm{H}_{2} \mathrm{O}\right)_{2}\right](\boldsymbol{\square})$ and cisplatin $(\boldsymbol{\Delta})$ against a panel of tumor cell lines as assessed by the MTT-dye reduction assay after 72-hour exposure. Each data point represents the arithmetic mean \pm sd of eight separate experiments. 


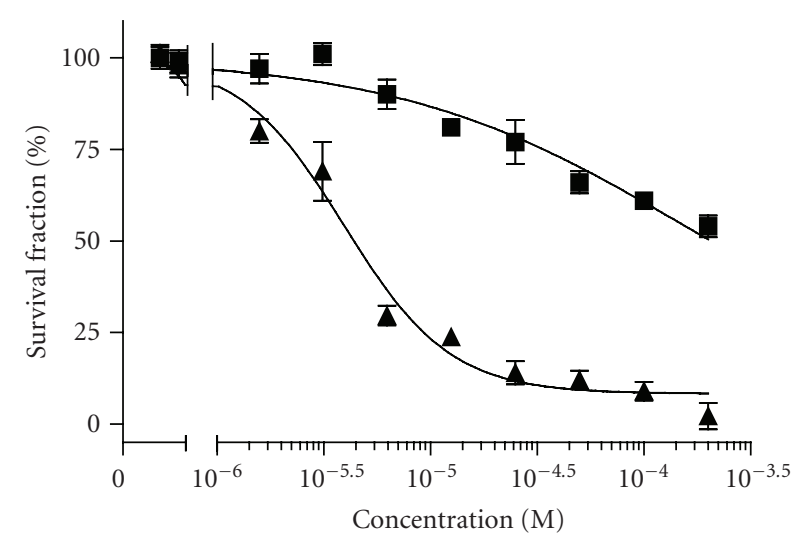

Figure 3: Cytotoxic effects of $\left[\mathrm{Au}(\mathrm{II}) \mathrm{Hp}_{-2 \mathrm{H}} \cdot\left(\mathrm{H}_{2} \mathrm{O}\right)_{2}\right]$ (ם) and cisplatin $(\boldsymbol{\Delta})$ against the human embryonic kidney cell line $293 \mathrm{~T}$ as assessed by the MTT-dye reduction assay after 72 hours exposure. Each data point represents the arithmetic mean \pm sd of eight separate experiments.

\subsection{In vitro cytotoxicity study of $\left[\mathrm{Au}(\mathrm{II}) \mathrm{Hp}_{-2 \mathrm{H}} \cdot\left(\mathrm{H}_{2} \mathrm{O}\right)_{2}\right]$ on human kidney cells in comparison to cisplatin}

The nephrotoxicity of the novel compound in an in vitro test system versus the established nephrotoxic drug cisplatin was estimated. The human embryonic kidney 293T cells were exposed for 72 hours to either cisplatin or $\left[\mathrm{Au}(\mathrm{II}) \mathrm{Hp}_{-2 \mathrm{H}} \cdot\left(\mathrm{H}_{2} \mathrm{O}\right)_{2}\right]$ and thereafter, their viability was detected with MTT-dye reduction assay (Figure 3). Throughout the tested range of concentrations the gold(II) complex proved to be only marginally cytotoxic and failed to cause $50 \%$ reduction of cell viability. In contrast, the referent drug cisplatin exhibited more pronounced cytotoxicity upon kidney cells with an IC 50 value of $3.87 \mu \mathrm{M}$.

\subsection{Induction of apoptosis following $\left[\mathrm{Au}(\mathrm{II}) \mathrm{Hp}_{-2 \mathrm{H}} \cdot\left(\mathrm{H}_{2} \mathrm{O}\right)_{2}\right]$ treatment}

Despite their principle modes of action, the majority of anticancer drugs share the distinction of being capable of recruiting the apoptotic cell death signaling pathways in malignant cells. Therefore, the ability of $\left[\mathrm{Au}(\mathrm{II}) \mathrm{Hp}_{-2 \mathrm{H}} \cdot\left(\mathrm{H}_{2} \mathrm{O}\right)_{2}\right]$ to evoke genomic DNA-fragmentation which is a key hallmark of programmed cell death was investigated. For this purpose, the exponentially growing SKW-3, K-562, HD-MY-Z, and MGH-U1 cells were exposed to equieffective concentrations of the gold(II) complex or cisplatin for 24 hours and thereafter, the levels of oligonucleosomal DNA fragmentation were assessed using a commercially available ELISA kit (Figure 4).

The results obtained indicate that $\left[\mathrm{Au}(\mathrm{II}) \mathrm{Hp}_{-2 \mathrm{H}} \cdot\left(\mathrm{H}_{2} \mathrm{O}\right)_{2}\right]$ is a potent apoptosis inductor causing similar level of DNA fragmentation as the referent drug cisplatin if applied at equipotent concentrations. The effect of the gold complex in MGH-U1 and HD-MY-Z was characterized by a straightforward concentration dependence, whereby the proportion of apoptotic cells arise increasing the concentration. In a contrast, the level of oligonucleosomal DNA-fragmentation was found to decrease at the highest concentration as compared to the lower ones in SKW-3. This result could be ascribed to the relative increase of the proportion of necrotic cells undetectable in our experimental setting. The gold complex failed to induce prominent DNA-fragmentation in $\mathrm{K}-562$ cells throughout the concentration range used. The level of apoptosis was significantly higher than the control only after exposure of cells to the highest concentration (twice the $\mathrm{IC}_{50}$ value).

\subsection{Intracellular accumulation of $\left[\mathrm{Au}(\mathrm{II}) \mathrm{Hp}_{-2 \mathrm{H}} \cdot\left(\mathrm{H}_{2} \mathrm{O}\right)_{2}\right]$}

The determination of the intracellular levels of gold attained after 30 minutes or 60 minutes of treatment of either $\mathrm{K}-562$ cells or HD-MY-Z with the $\mathrm{Au}(\mathrm{II})$ complex is depicted on Figure 5. A prominent time- and concentrationdependent pattern of gold accumulation is evident, whereby the intracellular levels in the K-562 cells are substantially higher as compared to those in HD-MY-Z cells. These data indicate that putative pharmacological targets of the tested compounds are readily accessible after a short incubation period.

\section{DISCUSSION}

To our best knowledge, the present study is the first one addressing the cytotoxic potential of stable monomeric octahedral $\mathrm{Au}(\mathrm{II})$ complexes. The antiproliferative activity of the novel compound was evaluated in a wide spectrum of cell lines, representative for some important types of human cancer. The results of the MTT-dye reduction assay unambiguously indicate that $\left[\mathrm{Au}(\mathrm{II}) \mathrm{Hp}_{-2 \mathrm{H}} \cdot\left(\mathrm{H}_{2} \mathrm{O}\right)_{2}\right]$ exerts potent cytotoxic/antiproliferative effect which in some cases is comparable to that of the referent cytotoxic drug cisplatin. Among the cell lines under evaluation the human T-cell leukaemia SKW-3 proved to be the most sensitive to $\mathrm{Au}(\mathrm{II})$ complex treatment, actually the $\mathrm{IC}_{50}$ value in these cells was lower than cisplatin. In the other leukaemia models, the relative potency of $\left[\mathrm{Au}(\mathrm{II}) \mathrm{Hp}_{-2 \mathrm{H}} \cdot\left(\mathrm{H}_{2} \mathrm{O}\right)_{2}\right]$ was somewhat lower but more or less comparable to that of cisplatin. Our experimental data indicated that cisplatin was prominently superior against the solid tumor-derived cell lines.

The clinically used platinum drugs as well as the gold antirheumatic agents are characterized by significant nephrotoxicity which is recognized as major dose-limiting factor. Hence, we sought to determine the nephrotoxic potential of $\left[\mathrm{Au}(\mathrm{II}) \mathrm{Hp}_{-2 \mathrm{H}} \cdot\left(\mathrm{H}_{2} \mathrm{O}\right)_{2}\right]$ versus the established nephrotoxin cisplatin. The transformed cell lines appear to be an attractive model among the in vitro test systems used for assessment of nephrotoxicity. They are more versatile than the primary cells on the one hand and retain most of the biochemical features of the normal kidney tissue on the other hand [25]. In the present study, 293T cells were used which have been recently characterized as a suitable model for in vitro assessment of nephrotoxicity [26-28]. The newly synthesized complex $\left[\mathrm{Au}(\mathrm{II}) \mathrm{Hp}_{-2 \mathrm{H}} \cdot\left(\mathrm{H}_{2} \mathrm{O}\right)_{2}\right]$ proves to be far less cytotoxic against kidney cells and in contrast to cisplatin, it fails to induce $50 \%$ inhibition of cellular viability. In contrast cisplatin was found to exert prominent cytotoxic 


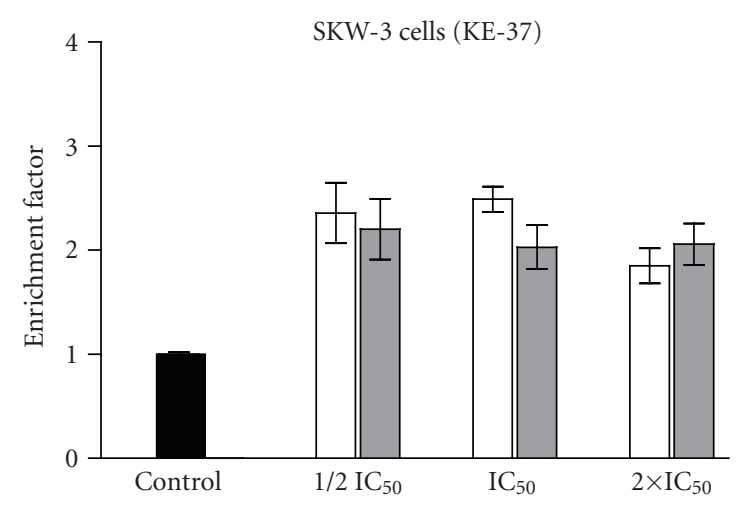

(a)

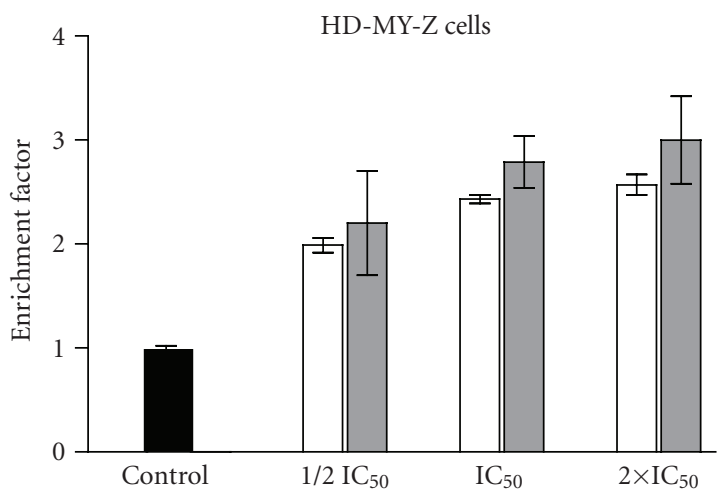

(c)

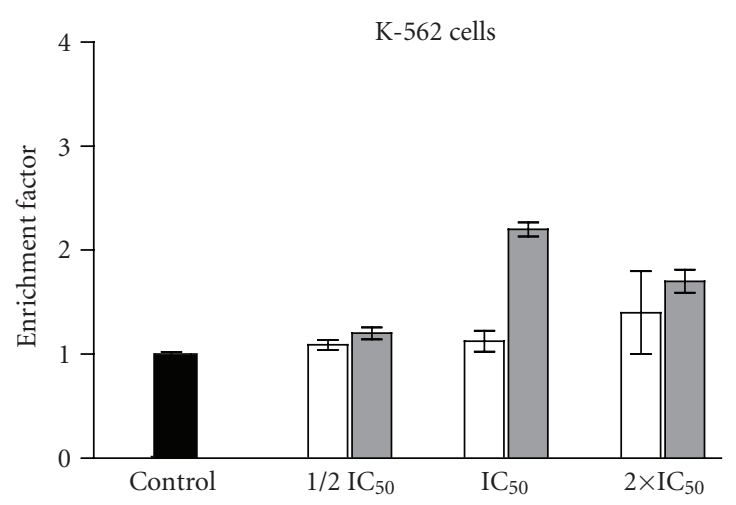

(b)

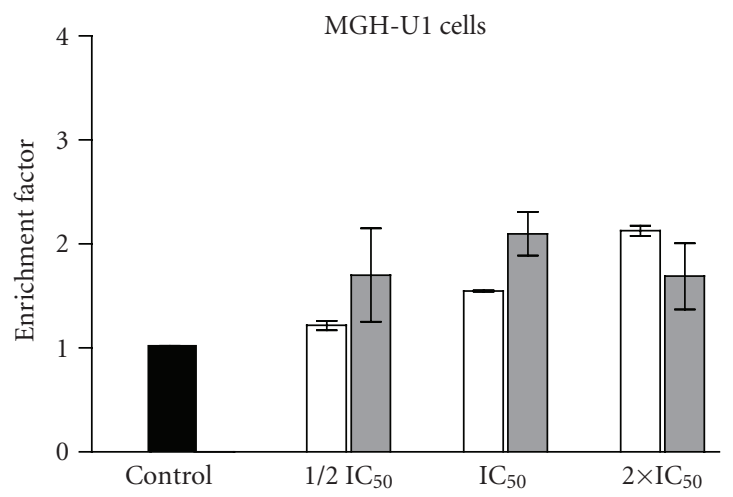

(d)

FIGURE 4: Internucleosomal DNA fragmentation in SKW-3, K-562, HD-MY-Z, and MGH-U1 cells after 24-hour exposure to equipotent concentrations of $\left[\mathrm{Au}(\mathrm{II}) \mathrm{Hp}_{-2 \mathrm{H}} \cdot\left(\mathrm{H}_{2} \mathrm{O}\right)_{2}\right]$ (white columns) or cisplatin (gray columns). The level of DNA fragmentation expressed as the corresponding enrichment factor ( $\mathrm{ef}=1$ in untreated control) was determined using "Cell Death Detection" ELISA (Roche Diagnostics).

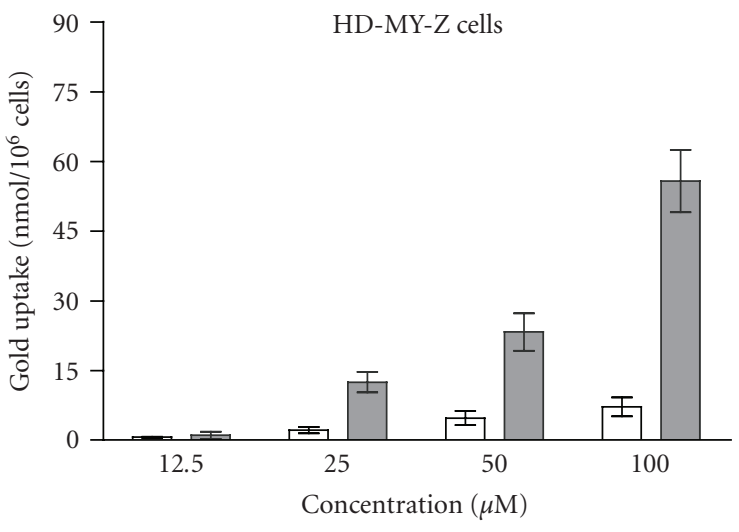

(a)

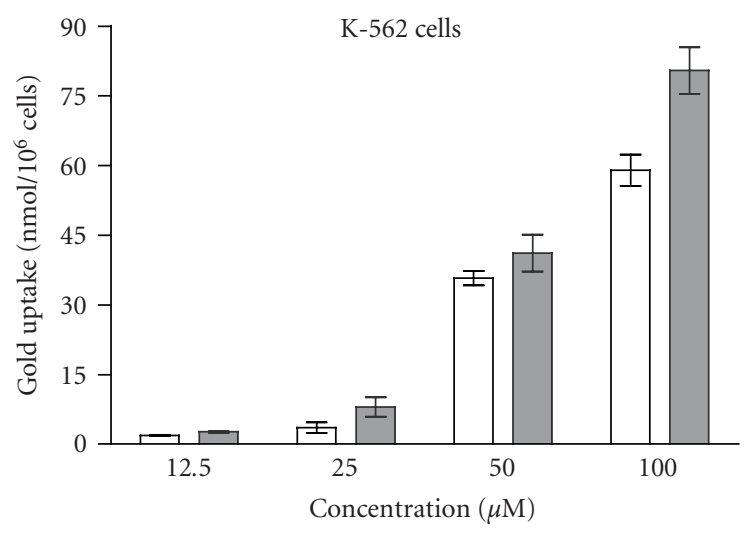

(b)

FIgURe 5: Intracellular accumulation of gold following $\left[\mathrm{Au}(\mathrm{II}) \mathrm{Hp}_{-2 \mathrm{H}} \cdot\left(\mathrm{H}_{2} \mathrm{O}\right)_{2}\right]$ treatment of HD-MY-Z or K-562 cells for 30 minutes (white columns) or 60 minutes (gray columns), means of 4 independent experiments.

effects with the $\mathrm{IC}_{50}$ value similar to those obtained in the cancer cell lines.

Another important objective of the present investigation was to determine the intracellular penetration of the gold complex. Although the specific mechanisms of the cytotoxi- city of gold species are not fully elucidated, there is a general consensus that they interact with intracellular targets, a feature which is common for most of the anticancer drugs [ 7 , 10]. Thus, the cellular accumulation of the drug appears to be a crucial prerequisite for optimal cytotoxic activity. The novel 
gold(II) complex is characterised by a significant intracellular accumulation which is more pronounced in the leukemic model K-562 than in HD-MY-Z Hodgkin's lymphoma. A possible explanation is the discrepancy between the cultures type in these cell lines. While the K-562 cells are suspended in the medium, the HD-MY-Z cells tend to attach to the bottom of the cultivation vessel forming monolayers. Conversely, the exposure area in K-562 cells is greater in comparison to that of the semiadherent HD-MY-Z.

In order to elucidate the mechanisms underlying the observed cytotoxicity of $\left[\mathrm{Au}(\mathrm{II}) \mathrm{Hp}_{-2 \mathrm{H}} \cdot\left(\mathrm{H}_{2} \mathrm{O}\right)_{2}\right]$, the level of DNA-fragmentation has been quantified. The induction of programmed cell death appears to be a common feature mediating the cytotoxic effects of anticancer agents and in particular of metal-based drugs $[1,4]$. The results reported here confirm the general character of this phenomenon: $\left[\mathrm{Au}(\mathrm{II}) \mathrm{Hp}_{-2 \mathrm{H}} \cdot\left(\mathrm{H}_{2} \mathrm{O}\right)_{2}\right]$ was found to induce apoptotic cell death in SKW-3, MGH-U1, K-562, and HD-MY-Z cells after 24-hour exposure. The low responsiveness of K-562 cells to the proapoptotic effects of $\left[\mathrm{Au}(\mathrm{II}) \mathrm{Hp}_{-2 \mathrm{H}} \cdot\left(\mathrm{H}_{2} \mathrm{O}\right)_{2}\right]$ is the most probable explanation for the discrepancy between its low sensitivity to the gold agent and its excellent intracellular accumulation patterns.

The present data for the $\mathrm{Au}(\mathrm{II})$ metalloporphyrin complex are in accordance with the effects established with structurally similar, octahedral Pt(III) complexes which are characterized by a significant cytotoxicity too [22]. The complex $\left[\mathrm{Au}(\mathrm{II}) \mathrm{Hp}_{-2 \mathrm{H}} \cdot\left(\mathrm{H}_{2} \mathrm{O}\right)_{2}\right]$ has an analogous structure with one of these $\mathrm{Pt}$ (III) complexes, both having octahedral structure with the metal center being coordinated in the porphyrin ring via the four pyrrolic nitrogens. The juxtaposition of their cytotoxicity shows that while the platinum complex is far more active against the chronic myeloid leukaemia LAMA-84 [18], the Au(II) complex studied exerts superior activity against the T-cell leukaemia SKW3 (KE-37). These data correlate well with the estimated specific inhibiting effect of gold species upon immune cells and T-cells in particular [7].

The selective uptake of porphyrins in malignant tissues/cells is due to complex mechanisms, among them the most important being the LDL-receptor mediated endocytosis of porphyrin/lipoprotein complexes formed in the circulation. Hence, porphyrins are employed as targeting moieties to ensure selective accumulation of cytotoxic agents into the solid tumor microenvironment [19-21]. The novel complex used in the present study demonstrated significant intracellular accumulation presumably mediated by formation of FCS-lipoprotein complexes and subsequent endocytosis. Due to the phototoxic properties of the ligand, a light-borne augmentation of the cytotoxicity of $\left[\mathrm{Au}(\mathrm{II}) \mathrm{Hp}_{-2 \mathrm{H}} \cdot\left(\mathrm{H}_{2} \mathrm{O}\right)_{2}\right]$ could not be ruled out and would be addressed in a further, more detailed evaluation of this compound.

All experimental data presented in this study indicate that $\left[\mathrm{Au}(\mathrm{II}) \mathrm{Hp}_{-2 \mathrm{H}} \cdot\left(\mathrm{H}_{2} \mathrm{O}\right)_{2}\right]$ is a biologically active compound with well-pronounced cytotoxic and proapoptotic properties against malignant cells. As compared to cisplatin, it is less cytotoxic for human kidney cells and this feature may prove to be advantageous.

\section{ACKNOWLEDGMENT}

The present study was financially supported by the National Science Fund of the Bulgarian Ministry of Education and Science through Grant no. WU-06/05.

\section{REFERENCES}

[1] T. Boulikas and M. Vougiouka, "Cisplatin and platinum drugs at the molecular level," Oncology Reports, vol. 10, no. 6, pp. 1663-1682, 2003.

[2] B. Desoize and C. Madoulet, "Particular aspects of platinum compounds used at present in cancer treatment," Critical Reviews in Oncology/Hematology, vol. 42, no. 3, pp. 317-325, 2002.

[3] L. Kelland, "The resurgence of platinum-based cancer chemotherapy," Nature Reviews Cancer, vol. 7, no. 8, pp. 573584, 2007.

[4] C. X. Zhang and S. J. Lippard, "New metal complexes as potential therapeutics," Current Opinion in Chemical Biology, vol. 7, no. 4, pp. 481-489, 2003.

[5] M. Galanski, M. A. Jakupec, and B. K. Keppler, "Update of the preclinical situation of anticancer platinum complexes: novel design strategies and innovative analytical approaches," Current Medicinal Chemistry, vol. 12, no. 18, pp. 2075-2094, 2005.

[6] B. Desoize, "Metals and metal compounds in cancer treatment," Anticancer Research, vol. 24, no. 3, pp. 1529-1544, 2004.

[7] C. F. Shaw III, "Gold-based therapeutic agents," Chemical Reviews, vol. 99, no. 9, pp. 2589-2600, 1999.

[8] P. Davis, "Auranofin," Clinics in Rheumatic Diseases, vol. 10, pp. 369-383, 1984.

[9] C. K. Mirabelli, R. K. Johnson, C. M. Sung, L. Faucette, K. Muirhead, and S. T. Crooke, "Evaluation of the in vivo antitumor activity and in vitro cytotoxic properties of auranofin, a coordinated gold compound, in murine tumor models," Cancer Research, vol. 45, no. 1, pp. 32-39, 1985.

[10] C. Gabbiani, A. Casini, and L. Messori, "Gold(III) compounds as anticancer drugs," Gold Bulletin, vol. 40, no. 1, pp. 73-81, 2007.

[11] B. P. Espósito and R. Najjar, "Interactions of antitumoral platinum-group metallodrugs with albumin," Coordination Chemistry Reviews, vol. 232, no. 1-2, pp. 137-149, 2002.

[12] P. Calamai, S. Carotti, A. Guerri, et al., "Biological properties of two gold(III) complexes: $\mathrm{AuCl}_{3}(\mathrm{Hpm})$ and $\mathrm{AuCl}_{2}(\mathrm{pm})$," Journal of Inorganic Biochemistry, vol. 66, no. 2, pp. 103-109, 1997.

[13] L. Messori, F. Abbate, G. Marcon, et al., "Gold(III) complexes as potential antitumor agents: solution chemistry and cytotoxic properties of some selected gold(III) compounds," Journal of Medicinal Chemistry, vol. 43, no. 19, pp. 3541-3548, 2000.

[14] G. Marcon, S. Carotti, M. Coronnello, et al., "Gold(III) complexes with bipyridyl ligands: solution chemistry, cytotoxicity, and DNA binding properties," Journal of Medicinal Chemistry, vol. 45, no. 8, pp. 1672-1677, 2002.

[15] A. Laguna and M. Laguna, "Coordination chemistry of gold(II) complexes," Coordination Chemistry Reviews, vol. 193195, pp. 837-856, 1999.

[16] P. Thornton, "The noble metals," Annual Reports on the Progress of Chemistry A, vol. 100, pp. 275-301, 2004. 
[17] J. L. Shaw, J. Wolowska, D. Collison, et al., "Redox noninnocence of thioether macrocycles: elucidation of the electronic structures of mononuclear complexes of gold(II) and silver(II)," Journal of the American Chemical Society, vol. 128, no. 42, pp. 13827-13839, 2006.

[18] G. Gencheva, D. Tsekova, G. Gochev, D. Mehandjiev, and P. R. Bontchev, "Monomeric Au(II) complex with hematoporphyrin IX," Inorganic Chemistry Communications, vol. 6, no. 3, pp. 325-328, 2003.

[19] C. Lottner, K.-C. Bart, G. Bernhardt, and H. Brunner, "Soluble tetraarylporphyrin-platinum conjugates as cytotoxic and phototoxic antitumor agents," Journal of Medicinal Chemistry, vol. 45, no. 10, pp. 2079-2089, 2002.

[20] C. Lottner, K.-C. Bart, G. Bernhardt, and H. Brunner, "Hematoporphyrin-derived soluble porphyrin-platinum conjugates with combined cytotoxic and phototoxic antitumor activity," Journal of Medicinal Chemistry, vol. 45, no. 10, pp. 2064-2078, 2002.

[21] C. Lottner, R. Knuechel, G. Bernhardt, and H. Brunner, "Combined chemotherapeutic and photodynamic treatment on human bladder cells by hematoporphyrin-platinum(II) conjugates," Cancer Letters, vol. 203, no. 2, pp. 171-180, 2004.

[22] G. Gencheva, D. Tsekova, G. Gochev, et al., "Synthesis, structural characterization, and cytotoxic activity of novel paramagnetic platinum hematoporphyrin IX complexes: potent antitumor agents," Metal-Based Drugs, vol. 2007, Article ID 67376, 13 pages, 2007.

[23] T. Mosmann, "Rapid colorimetric assay for cellular growth and survival: application to proliferation and cytotoxicity assays," Journal of Immunological Methods, vol. 65, no. 1-2, pp. 55-63, 1983.

[24] S. M. Konstantinov, H. Elbl, and M. R. Berger, "BCRABL influences the antileukaemic efficacy of alkylphosphocholines," British Journal of Haematology, vol. 107, no. 2, pp. 365-374, 1999.

[25] J.-P. Morin, M. E. de Broe, W. Pfaller, and G. Schmuck, "Nephrotoxicity testing in vitro: the current situation: ECVAM nephrotoxicity task force report 1," ATLA, vol. 25, no. 5, pp. 497-503, 1997.

[26] T. Hamada, T. Sasaguri, A. Tanimoto, et al., "Apoptosis of human kidney 293 cells is promoted by polymerized cadmium-metallothionein," Biochemical and Biophysical Research Communications, vol. 219, no. 3, pp. 829-834, 1996.

[27] W.-P. Mao, J.-L. Ye, Z.-B. Guan, et al., "Cadmium induces apoptosis in human embryonic kidney (HEK) 293 cells by caspase-dependent and -independent pathways acting on mitochondria," Toxicology in Vitro, vol. 21, no. 3, pp. 343-354, 2007.

[28] X. Zhou, G. Yang, C. A. Davis, et al., "Hydrogen peroxide mediates FK506-induced cytotoxicity in renal cells," Kidney International, vol. 65, no. 1, pp. 139-147, 2004. 


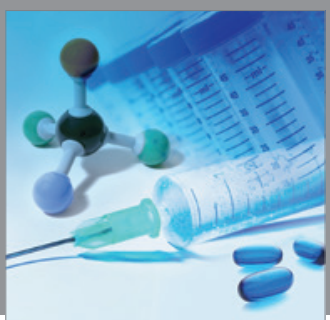

International Journal of

Medicinal Chemistry

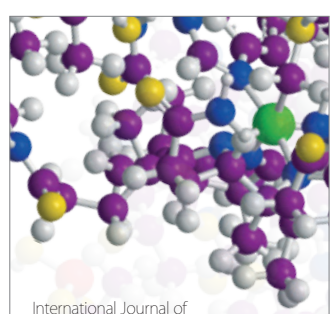

Carbohydrate Chemistry

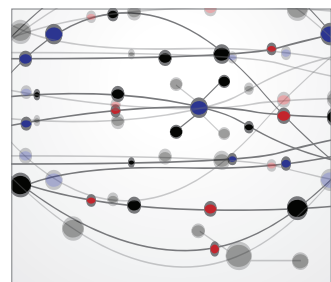

The Scientific World Journal
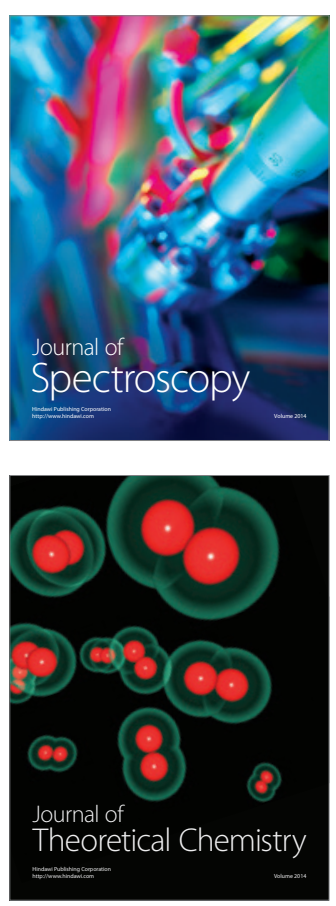
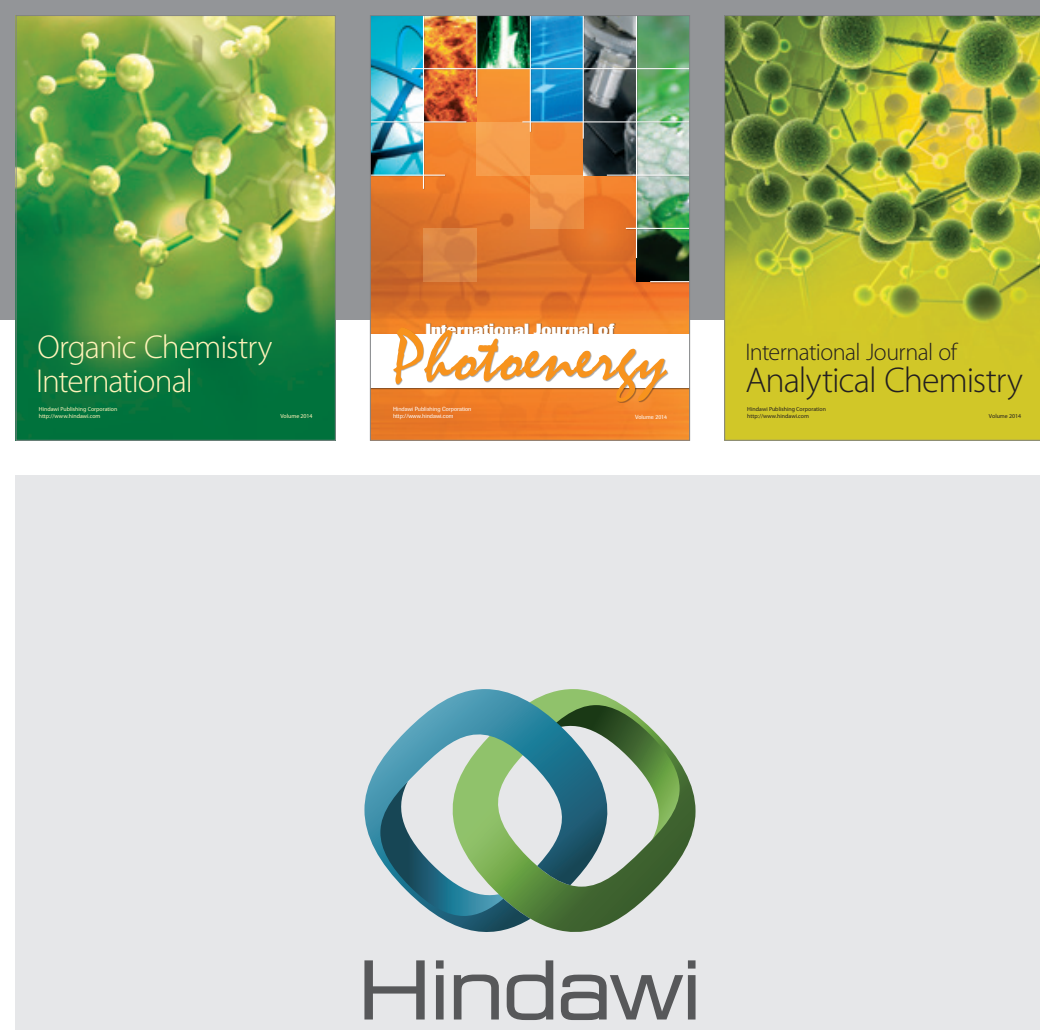

Submit your manuscripts at

http://www.hindawi.com
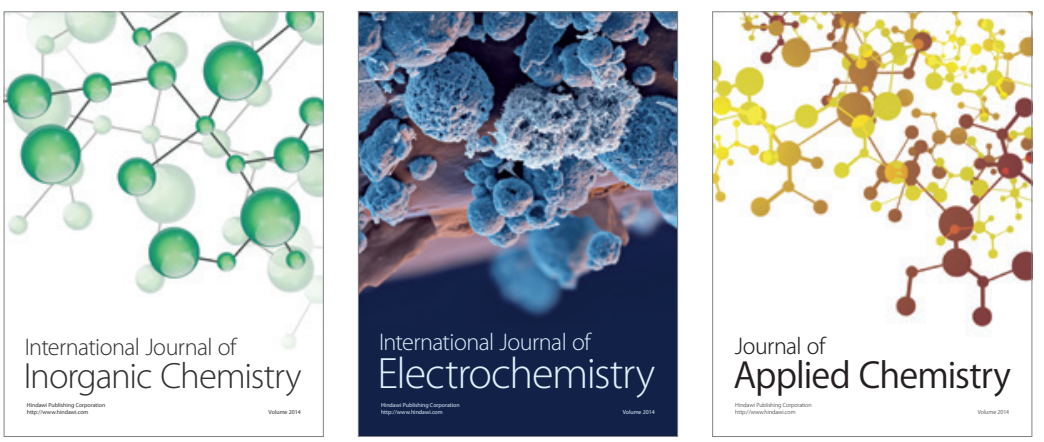

Journal of

Applied Chemistry
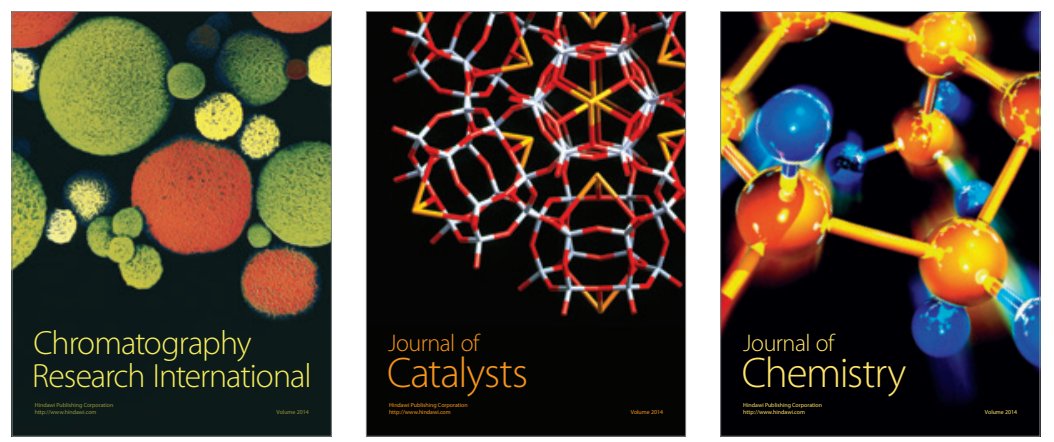
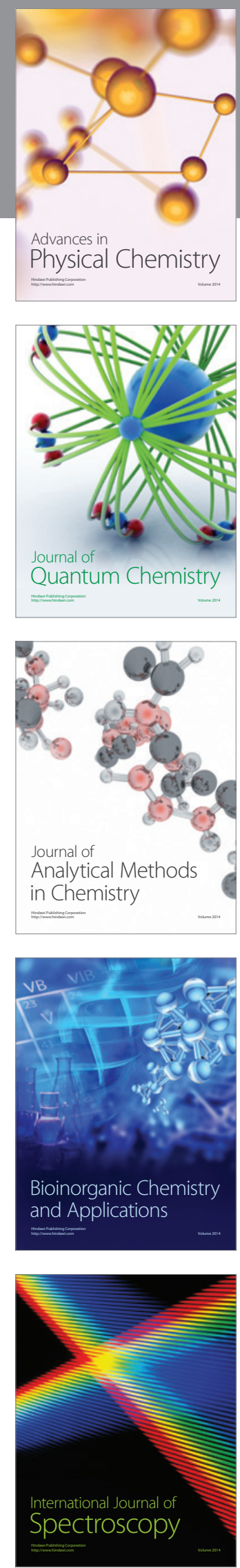